\title{
CONTRAPUNTO SOBRE LA MODIFICACIÓN AL ARTÍCULO 234 DEL CÓDIGO CIVIL RELATIVO A LA FACULTAD DE LOS PADRES DE CORREGIR A LOS HIJOS
}

\begin{abstract}
La Dirección de la Revista Chilena de Derecho invitó a participar en la sección de Ensayos y Crónicas a los profesores de Derecho: Jorge Baraona* (en adelante J.B.), de la Universidad de los Andes y Mauricio Tapia** (en adelante M.T.), de la Universidad de Chile, para que respondieran cuatro preguntas relativas a un tema de Derecho Civil que ha tenido eco en diversas columnas de opinión y foros de debate: los intentos para derogar o modificar el artículo 234 del Código Civil en relación con el castigo moderado de los hijos. Las preguntas formuladas fueron las siguientes:
\end{abstract}

\section{1. ¿QUÉ OPINIÓN GENERAL LE MERECE A USTED EL PROYECTO DE LEY \\ CONTENIDO EN EL BOLETÍN No 5.500-18 \\ QUE SUSTITUYE EL ARTÍCULO 234 DEL \\ CÓDIGO CIVIL EN REFERENCIA A LA \\ FACULTAD DE LOS PADRES DE \\ CORREGIR A LOS HIJOS?}

J.B.: La verdad es que son varios los proyectos de ley en que se ha propuesto la modificación del artículo 234 del Código Civil, a los efectos de prohibir los castigos físicos moderados a los hijos. Uno de ellos es el Boletín 5.500-18, de iniciativa parlamentaria, que está en la Cámara de Diputados, otro es un proyecto de ley que introduce una serie de modificaciones a los Tribunales de Familia y que se tramita actualmente en el Senado, radicado en al Comisión de Constitución, Legislación, Justicia y Reglamento. En este contexto, en diciembre del año 2007, esta última Comisión aprobó una indicación del Ejecutivo por la cual se explicita que la facultad de los padres para corregir a sus hijos, conforme con el artículo 234 del Código Civil, no puede autorizar el castigo físico.

Me he manifestado contrario a estas iniciativas, pues, estimo que una medida como

* Doctor en Derecho de la Universidad de Navarra, Licenciado en Derecho de la Pontificia Universidad Católica de Chile, Abogado de Barahona, Bulnes y Cía.

** Master en Derecho Privado y Candidato a Doctor en Derecho por la Universidad de Paris XII, Francia. Abogado, Licenciado en Ciencias Jurídicas y Sociales de la Universidad de Chile. la que se propone es equivocada, desde muchos puntos de vista. Tal vez el argumento más de fondo por la cual miro con recelo la modificación que se propone, es que lesiona la autoridad paternal. Creo que los padres tienen un derecho-deber de educar a sus hijos y en el ejercicio de esta esencial misión, debe dotárseles de la autoridad suficiente. Por ello, la corrección de los hijos por parte de sus padres puede necesitar, en ciertos casos excepcionales, de castigos físicos moderados, por lo que prohibirlos por ley puede suponer privar a los hijos de un bien y debilitar la autoridad paterna.

Comprendo perfectamente que esta opinión pueda resultar chocante para la sensibilidad contemporánea, que lucha por excluir la violencia de cualquier ámbito y concretamente por favorecer modelos de relaciones sociales basados en el diálogo, el reconocimiento mutuo y en general la reflexión. La psicología moderna está en esta misma línea, pero creo que no hay razón para cambiar la norma.

Yo no estoy promoviendo la violencia en contra de los hijos, sólo que no se prive a los padres de su facultad de corregirlos sin menoscabo para ellos, estando sin embargo consciente que la norma original del Código era fuerte. En efecto, decía el artículo 233:

"El padre tendrá la facultad de corregir y castigar moderadamente a sus hijos y si esto no alcanzare, podrá imponerles la pena de detención hasta por un mes en un establecimiento correccional.

Bastará al efecto la demanda del padre y el juez en virtud de ella expedirá la orden de arresto. 
Pero si el hijo hubiere cumplido dieciséis años, no ordenará el juez el arresto, sino después de calificar los motivos y podrá extenderlo hasta por seis meses a los más. arresto".

El padre podrá a su arbitrio hacer cesar el

La evolución de la sociedad llevó a una modificación de esta norma por Ley 4.447 de 1928, llamada comúnmente de "Protección de Menores", que le dio una nueva redacción al artículo 233, para dejarlo de la siguiente manera:

"El padre tendrá la facultad de corregir y castigar moderadamente a sus hijos.

Cuando lo estimare necesario, podrá recurrir al tribunal de menores, a fin de que se determine sobre la vida futura del menor por el tiempo que se estime más conveniente, el cual no podrá exceder del plazo que le falte para cumplir veinte años de edad.

Las resoluciones del juez de menores no podrá ser modificadas por la sola voluntad del padre".

Se advierte, asimismo, como lo destacaba el profesor Manuel Somarriva (Evolución del Código Civil Chileno, segunda edición, Temis, 1984, pp. 84 y 85), cómo con el tiempo ha ido disminuyendo la autoridad familiar en favor de instituciones estatales, especialmente respecto de facultades que puedan estimarse como incompatibles con el pleno reconocimiento de las garantías constitucionales, las que también deben ser predicadas en favor de los hijos.

Una última etapa de la evolución de la norma, la encontramos con la aprobación de la Ley 19.585, de 1998, por la cual se dispone, ahora en el artículo 234:

"Los padres tendrán la facultad de corregir a los hijos, cuidando que ello no menoscabe su salud ni su desarrollo personal.

$\mathrm{Si}$ se produjese tal menoscabo o se temiese que ocurra, el juez a petición de cualquier persona o de oficio, decretará medidas en resguardo del hijo, sin perjuicios de las sanciones que corresponda aplicar por la infracción.

Cuando sea necesario para el bienestar del hijo, los padres podrán solicitar al tribunal que determine sobre la vida futura de aquel por el tiempo que estime más conveniente, el cual no podrá exceder del plazo que le falte para cumplir dieciocho años de edad.

Las resoluciones del juez no podrán ser modificadas por la sola voluntad de los padres".

Lo que se pretende con la modificación actualmente propuesta, entonces, es prohibir el castigo físico al menor, aunque sea moderado. Sin embargo, creo que la norma como está redactada actualmente, está bien pensada, pues fija el criterio que hace ilegítima una corrección física: cuando se causa un menoscabo al hijo. Es decir, cuando por efecto del castigo el niño sufre una pérdida neta y no un beneficio. Y aquí está la clave del asunto: para los que piensan que cualquier golpe a un niño, aunque sea leve o moderado, tiene un impacto negativo en su personalidad y no podría nunca significarle un bien, obviamente interpretarán la norma, incluso tal cual está, como prohibitiva de todo castigo físico. En cambio, para quienes pensamos que el castigo físico moderado puede suponer un bien al niño, si ello le conduce a modificar una conducta que no parece adecuada, concluimos que la actual redacción autoriza castigos moderados.

Por lo mismo, lo que quiere hacerse con la reforma que comentamos es precisar que, más allá del menoscabo o no al menor, el castigo físico está prohibido, cualquier sea su entidad, y es en lo que no concuerdo.

M.T.: Existen tres proyectos de ley actualmente en curso que persiguen un mismo objetivo, aunque con algunos matices: erradicar el castigo físico contra los hijos, modificando el artículo 234 del Código Civil (Boletines $\mathrm{N}^{\circ}$ 5.685-07, 4.438-07 y 5.506-18).

En particular, el contenido en el Boletín $\mathrm{N}^{\circ} 5.506-18$ por el que se me interroga, me parece que, ante todo, adolece de serios errores de técnica legislativa. El más evidente es que la proposición de modificación pretende introducir una frase que señale que los padres "en ningún caso podrán golpearlos” (a los niños), al final del actual inciso primero del mencionado artículo 234. No obstante, entre los fundamentos de ese proyecto (que formará parte de su "historia legislativa"), se señala expresamente que a pesar de esta modificación, siempre será posible que los padres puedan corregir 
a sus hijos "cuidando de que las palmadas que les den no sean de tal naturaleza que menoscabe (sic) su salud o su desarrollo personal". Así, entre los fundamentos y el texto del proyecto existe una ostensible contradicción, pues no es lógico que se proponga proscribir cualquier golpe a los niños y, al mismo tiempo, se afirme que, en todo caso, siempre se les podrán seguir dando algunas "palmadas".

Es por esto que, desde el punto de vista de la técnica legislativa, prefiero la redacción del proyecto contenido en el Boletín 4.438-07 (que se enmarca en la modificación de los Tribunales de Familia), y que propone reformar ese artículo en el sentido de que el derecho a corregir a los hijos debe ajustarse a la ley y a la Convención sobre los Derechos del Niño, incorporada a nuestra legislación, y que proscribe toda forma de perjuicio físico contra los niños.

\section{2. ¿CONSIDERA USTED PROPIO DE LA DISCIPLINA DEL DERECHO CIVIL LA REGULACIÓN DEL IMPEDIMENTO DE GOLPEAR A LOS HIJOS O LA PROTECCIÓN ANTE EL MENOSCABO DE LA SALUD Y EL DESARROLLO PERSONAL DE LOS MENORES QUE PUDIERA SER AFECTADO POR ESTE ARTÍCULO DEL CÓDIGO CIVIL?}

J.B.: Me parece que en materia de menores la legislación debe ser sensible, pues es lamentable constatar que con los niños se abusa mucho. No creo que la actual norma invada ilegítimamente el área de la autonomía familiar. Distinto es respecto de la norma que se propone en el proyecto, pues, lo que quiere hacer es prohibir a los padres que puedan darle una palmada a sus hijos, por ejemplo. Y aquí sí veo lesionada la autonomía de la familia, que estimo indispensable proteger. Por lo demás, así lo ordena la propia Constitución en su artículo primero. No puede pensarse que por la vía legislativa vamos a terminar con la cultura de la "cachetada". Reclamo el derecho de los padres de un menor para decidir qué estilo de corrección están dispuestos a ejercer: con o sin palmadas. No es función de la ley prohibir la corrección moderada, pues eso daña el bien de los hijos, el bien de la familia y la autoridad de los mismos padres.

M.T.: Esta pregunta conduce a interrogarse sobre el sentido de esta norma y de la propuesta de reforma. El Derecho Civil regula las relaciones privadas, tanto en sus aspectos patrimoniales como personales. En materia de familia, la regulación civil siempre ha sido tributaria de la historia, esto es, ha respondido a un estado determinado de la evolución social. En este ámbito es particularmente válida la afirmación de que "las leyes están hechas para los hombres, y no los hombres para las leyes". Se trata de leyes históricas y locales, que mutan de tiempo en tiempo con los cambios experimentados por cada sociedad. Es por eso que los intentos de hacer "ingeniería social" mediante las leyes civiles siempre han fracasado, pues la ley civil no tiene por función el provocar cambios sociales o el frenarlos.

En atención a lo expuesto, los poderes de la ley civil en materia de la familia son más bien limitados, pues se trata de regulaciones neutras que deben dar acogida a las diferentes nociones y convicciones sobre la familia y, en definitiva, sobre el bien. El resto no son más que declaraciones de buenas intenciones.

Como consecuencia de lo anterior, el derecho de familia, particularmente en el siglo $\mathrm{XX}$, se ha concentrado en la resolución de los conflictos familiares, que la solidaridad y la cooperación familiar (que es el estado normal) no pueden solucionar. Un buen ejemplo es la disposición civil que declara solemnemente que los hijos deben respeto y obediencia a los padres, esto es, en definitiva, impulsa a quererlos. Es un buen propósito, pero en la ausencia de tal respeto y obediencia, la ley civil no puede constreñir a los hijos a amar a sus padres, sino solo a mantenerlos (derecho de alimentos) en caso de necesidad, si los lazos de afecto no logran tal objetivo espontáneamente. Es en el conflicto al interior de la familia donde el derecho civil tiene un papel importante, porque el resto queda entregado al modelo familiar que las personas decidan libremente otorgarse.

En ese contexto, la educación de los hijos es una cuestión que corresponde a cada 
familia, y la ley civil tiene poquísimas herramientas para contribuir a lo que se entiende por una "buena educación". Estas se reducen a velar para que en el conflicto de sus padres su cuidado personal se entregue al más apto, y que se contribuya materialmente a su mantención y educación. Los mecanismos más idóneos para lograr que los hijos se eduquen correctamente no provienen de la ley civil, sino de medidas asistenciales que les proporcionen en igualdad de condiciones un derecho a una buena alimentación, educación y salud, cuestión que presenta en Chile escandalosas y tristes asimetrías.

Asimismo, las medidas más idóneas para evitar violencias contra los niños al interior de la familia tampoco pertenecen a la regulación civil (no por un "purismo conceptual", sino por que esta carece de herramientas apropiadas para lograr ese objetivo, como señalé). Para evitar violencias contra los niños debe apuntarse más bien a mecanismos asistenciales que apoyen social y psicológicamente a los padres, y a correctivos penales que castiguen las violencias más graves.

En definitiva, los poderes de la ley civil en la educación de los hijos son limitadísimos, y las declaraciones contenidas en el artículo 234 en cuestión, son más bien buenas intenciones sin efecto práctico cuando no están acompañadas de las medidas que se mencionaron.

\section{3. ¿PIENSA USTED QUE LA SITUACIÓN JURÍDICA ACTUALMENTE VIGENTE EN EL CÓDIGO CIVIL, RELATIVA A LA CORRECCIÓN MODERADA DE LOS HIJOS, PUEDE SER ESGRIMIDA PARA VULNERAR DERECHOS DE LOS HIJOS O PARA JUSTIFICAR SITUACIONES DE VIOLENCIA INTRAFAMILIAR?}

J.B.: De ninguna manera. Ya he explicado que el límite a la corrección es el menoscabo, por lo que nadie en el ejercicio de este derecho-deber de corregir a sus hijos, puede sentirse con la facultad de maltratarlos. Creo que un sensato criterio doméstico debe llevar a distinguir entre lo que es una castigo moderado y un acto de violencia. Puede que factores culturales o emocionales hagan fallar a algunos padres, y ahí hará falta la intervención de instituciones estatales: tribunales, Sename, etc.

M.T.: Lamentablemente todos los derechos pueden ser abusados y esgrimidos para perjudicar otros de igual o mayor jerarquía. Sin embargo, nuestra legislación (como la mayoría de los ordenamientos jurídicos) cuenta con figuras para corregir tales abusos o desviaciones del fin que se tuvo en vista al reconocer tales derechos. Así, si indebidamente se pretende esgrimir la facultad de corregir a los hijos para justificar acciones que lesionen sus derechos, es posible recurrir a la ley de violencia intrafamiliar, o, si son de una mayor gravedad, a la ley penal. Pero, evidentemente, lo anterior no puede llevar a la conclusión de que para eliminar los abusos deban eliminarse los derechos. Eso equivaldría a juzgar una institución social por sus hipertrofias, y no por su estado normal de funcionamiento.

\section{4. ¿CREE USTED QUE ES POSITIVO O NEGATIVO EL CASTIGO FÍSICO MODERADO QUE PUDIERA SER EMPLEADO EN LA EDUCACIÓN DE LOS HIJOS?}

J.B.: Sobre el castigo físico como estrategia de educación, puede haber mucha y legítima discusión. Lo que no me parece aceptable es que se prohíba por ley la corrección moderada, estandarizando así un modelo de educación, en circunstancias que es resorte de los padres decidirlo. Los padres tenemos el deber de educar y somos responsables de la mala crianza de nuestros hijos, tanto así que en mismo Código Civil, artículo 2321, se hace civilmente responsables a los padres de los delitos o cuasidelitos cometidos por los hijos menores y que "conocidamente provengan de mala educación, o de los hábitos viciosos que les han dejado adquirir". Personalmente estimo que en casos excepcionales una palmada le hace bien a un hijo.

M.T.: Esta es una cuestión que excede el ámbito netamente jurídico y lleva a pronunciarse sobre cuestiones que afectan las creen- 
cias o las costumbres de las personas. Es cierto que en la época de la codificación de nuestras leyes civiles (siglo XIX), la corrección mediante el castigo físico era más tolerada que en la actualidad, quizá en gran medida producto de que en algunas religiones la falta va asociada necesariamente al castigo. La evolución que vemos en la actualidad es un fenómeno más bien propio de las culturas occidentales, y no solo de nuestro país. Y prueba de ello es que varios países discuten en la actualidad la introducción de reformas similares a la comentada.

La "palmada" a los hijos siempre ha existido, lo que ocurre es que en la actualidad existe una menor tolerancia a esas formas de violencia, lo que genera, a su vez, una mayor ventilación pública de tales comportamientos.

Podríamos discutir ampliamente, sobre la base de estudios de psicología o sociología, si tales castigos benefician o perjudican la educación de los hijos. Podríamos sostener, así, por una parte, que tales castigos físicos muestran a los niños, de una manera nítida e inmediata, que existen ciertos límites que no pueden sobrepasar, siendo de esa forma una especie de enseñanza primaria de la "ley penal" que deberán respetar en su adultez (o, incluso, del "pecado" que deberán expiar, para aquellas familias que profesan el credo mayoritario en Chile). Por otra parte, podríamos argumentar que son el diálogo y la persuasión las únicas formas de imprimir límites duraderos, y que es posible corregir una falta sin castigo. Y tras estos argumentos no solo se encuentran razones "científicas", sino convicciones morales o religiosas, e incluso di- ferentes mentalidades que van unidas a la circunstancia de que en toda sociedad conviven personas pertenecientes a distintas generaciones, que han crecido en diferentes estadios de la evolución social. Una prueba de ello es el amplio debate que ha generado esta eventual reforma y lo relativamente irreconciliable que parecen las posiciones.

Así, en estas materias parece imposible llegar a acuerdos permanentes, que dejen a todos completamente conformes. En efecto, en estos temas, por las cuestiones de fondo que subyacen, solo podemos llegar a consensos transitorios.

Al respecto, pareciera que en nuestro país existe actualmente un amplio consenso acerca de que los castigos a los niños no pueden exceder ciertos límites: no es tolerada una violencia física o psíquica permanente o grave, que haga imposible la convivencia al interior de la familia, y por esto tales conductas se reprimen mediante la ley de violencia intrafamiliar (o incluso la ley penal).

Fuera de esos casos extremos, la pregunta de si una simple "palmada" esporádica y sin secuelas físicas es o no tolerable, no tiene respuestas categóricas en nuestra sociedad actual. No existiendo consenso, me parece prudente dejar esa decisión a cada familia. Pero insisto que, en todo caso, la prevención de los excesos que puedan cometerse pasa por medidas asistenciales (de educación y apoyo psicológico a los padres), y que la corrección de los mismos pertenece a la ley penal, siendo los poderes de la ley civil insuficientes para evitar aquellos o para reprimir estos. 
